\title{
Retinal Haemorrhage in Himalayan Mountaineers
}

\author{
Capt RE MacLaren
}

$\mathrm{MB}, \mathrm{ChB}, \mathrm{FRGS}, \mathrm{RAMC}(\mathrm{V})^{*}$

\author{
334 Amb Trn (V) \& Expedition Medical Officer, Oxford University OTC \\ Honorary SHO, Department of Ophthalmology, University of Oxford
}

SUMMARY: The fundi of 14 climbers were monitored on ascent to 6000 metres over a 15 day period in the Nepal Himalaya. A total of 4 climbers experienced symptomless haemorrhages. These haemorrhages were not secondary to changes in haemoglobin concentration, nor did they appear correlated to the use of acetazolamide. The risk of developing retinal haemorrhage was, however, significantly greater in the better acclimatized individuals. Possible reasons for this relationship are discussed.

\section{Introduction}

Acute mountain sickness (AMS) is a condition that should be familiar to all mountaineers. First described in details in 1913 (1), it had previously been known as "soroche" or "puna" to the Andean Indians, and was thought to be related to poisonous vapours from the metal ores of the high mountains (2). Distinct clinical entities of the disease are now recognised (3). The familiar benign form of nausea, headaches, cough and breathlessness affects all climbers to a variable degree, and is probably the result of the normal physiological changes associated with acclimatization, rather than any distinct pathological process. The more severe forms are high altitude pulmonary oedema (HAPE) and high altitude cerebral oedema (HACE). These are life-threatening emergencies requiring immediate evacuation and treatment with oxygen and diuretics or dexamethasone. Knowledge of these conditions should be a particular priority to military personnel, when there may be a need to rapidly deploy troops to high altitudes. Ironically, much was learnt about AMS when thousands of Indian troops were unwisely flown up to Leh $(3500 \mathrm{~m})$ in Ledakh to face wellacclimatized Chinese soldiers approaching from Tibet. Almost 2000 of these men were incapacitated with the effects of acute mountain sickness (4). Indeed, this was the first clear account of retinal haemorrhage occurring at altitude, later confirmed in subsequent reports (5-9).

The pathogenesis of high altitude retinal haemorrhage is poorly understood, often being detected in symptomless individuals. Incidences of about $39-40 \%$ have been

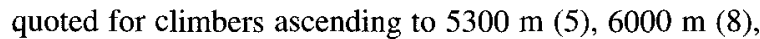
and $8000 \mathrm{~m}(6)$, but only by repeated examination of the fundi of climbers; a complaint of visual symptoms is rare and usually only occurs if haemorrhage is very large or occludes the macula (7). Thus the detection of isolated small haemorrhages is usually without consequence, however, this is a pathological process involving vessels of the central nervous system. Is the appearance of retinal haemorrhage related to the onset of AMS? Could it be used as a warning sign for impending high altitude cerebral oedema?
The aim of this study was therefore to explore further the factors that may predispose to retinal haemorrhage by monitoring the fundi and development of typical AMS symptoms (10) in climbers ascending a $6000 \mathrm{~m}$ peak in Nepal. Acetazolamide (Diamox) used for acclimatization (11) also lowers intraocular pressure, and a severe secondary polycythaemia (from chronic hypoxia) could theoretically lead to retinal haemorrhage (12); these factors were also included in the analysis.

\section{Methods}

The study group consisted of 14 climbers (12 male an $\$$ 2 female) from Exercise Blue Monsoon, organised bs Oxford University Officers' Training Corps. This study is relatively unique amongst other altitude studies, in tha the climbers were well matched, being of a similar age (19-26 yrs), and none having previously ascended above $2000 \mathrm{~m}$. The group took 15 days to climb from Kathmandu $(1200 \mathrm{~m})$ along the Rolwaling Himal and attempt two peaks: Mt. Lambochang (5984 m successful) and Mt. Pachermo (6273 m - unsuccessful), before descending through Namche Bazaar to fly back to Kathmandu from Lukla (Fig. 1). Blood was taken for haemoglobin estimations immediately before leaving, and a few days after return to sea level. At their own decision, 6 climbers took acetazolamide for at least 7 days before attempting the peaks. Fundi were examined by the medical officer (an ophthalmologist) at sea level, $2000 \mathrm{~m}$ $4000 \mathrm{~m}$ and immediately after descent from the highes peak at almost $6000 \mathrm{~m}$. Examination was by direct ophthalmoscopy through tropicamide-induced pupil dilatation at all stages, and any haemorrhages seen were drawn on a pre-prepared fundus chart. At the same time, a history of altitude-related symptoms was recorded to assess the degree of AMS experienced by each subject (Table 1). Continued acetazolamide use was also confirmed at these stages where appropriate.

Statistical analysis tested the hypotheses that (a) retinal o haemorrhage was unrelated to an increase in haemoglobin concentration and (b) retinal haemorrhage was unrelated to the severity of AMS (i.e. number of symptoms). Changes in haemoglobin concentration were assumed to 


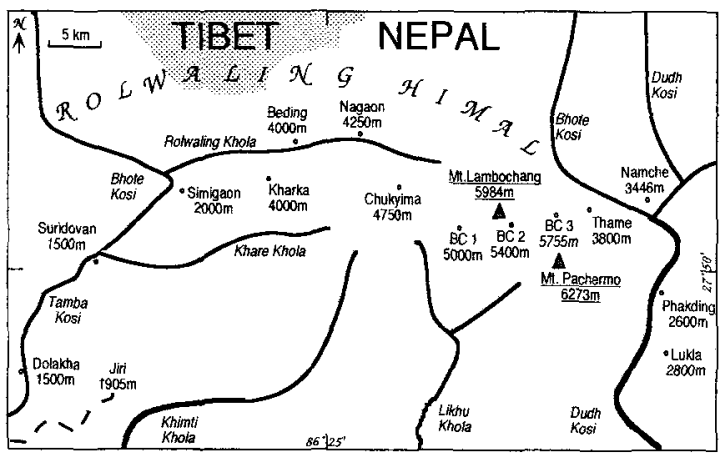

Key: $\sim$ road $\sim$ river camp A peak $B C=$ base camp

Fig. 1: Map of route through Rolwaling Himal:

follow a normal distribution, and compared by the paired t-test for differences between the mean change in the group with haemorrhages to those with normal fundi. The distribution of the number of symptoms between those with haemorrhages and those with normal fundi was ranked, and compared by the Mann-Witney $U$ test.

\section{Results}

A total of 4 of the 14 climbers showed small retinal haemorrhages after the ascent to $6000 \mathrm{~m}$ (an additional climber was noted to have a small haemorrhage, but was excluded from the study as he had missed the preexpedition check-up). The number of symptoms of AMS, haemoglobin changes, acetazolamide use and occurrence of retinal haemorrhage can be seen in Table 2. In the 4 positive cases, the haemorrhages were all smaller than one disc diameter. J.C. and J.L. had only one haemorrhage, O.H. had two haemorrhages in one eye, whilst J.H. had one haemorrhage in each eye. All haemorrhages were flame or wedge shaped, with an orientation consistent with origin from the nerve fibre layer and located within two disc diameters of the optic disc. No haemorrhages were either in contact with arteries or veins or involving the vitreous, nor did they cause any field defects that could be detected by basic clinical examination. All haemorrhages had resolved at the postexpedition check-up in Oxford 3 weeks later.

Table 1 shows the incidences of symptoms of AMS at different altitudes. Headache and shortness of breath were the commonest symptoms amongst the 14 member team. No symptoms were felt at $2000 \mathrm{~m}$, only a few complained at $4000 \mathrm{~m}$ but this number more than doubled on ascent to $6000 \mathrm{~m}$. Fortunately, only one person at $6000 \mathrm{~m}$ complained of the more severe symptom of incoordination.

Table 2 shows the relationship of the occurrence of haemorrhages to changes in haemoglobin, use of acetazolamide and number of symptoms of AMS. The mean increase in haemoglobin was $0.60 \mathrm{~g} / \mathrm{dl}^{3}$ in those with haemorrhage and $0.05 \mathrm{~g} / \mathrm{dl}^{3}$ in those without; this
Retinal Haemorrhage in Mountainee

Table 1

Incidences of symptoms of benign mountain sickness at increasing altitude (after Hackett ${ }^{10}$ )

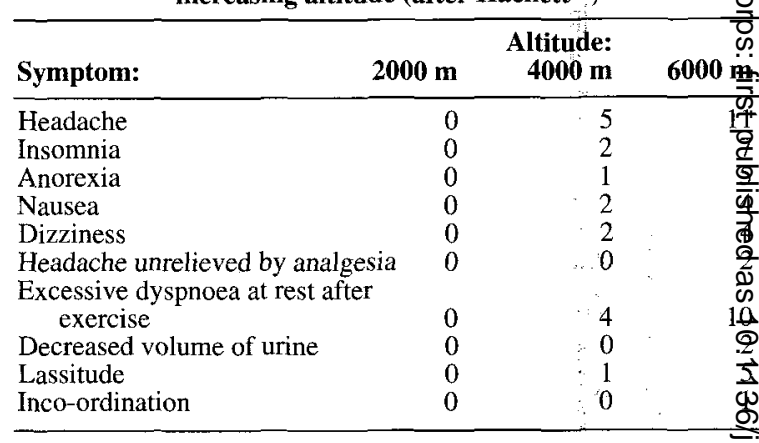

Table 2

Relationship of haemoglobin changes, symptoms of mountain sickness and use of acetazolamide to development of retinal haemorrhage

\begin{tabular}{|c|c|c|c|c|c|c|}
\hline & $\begin{array}{l}\text { haem } \\
\text { before }\end{array}$ & $\begin{array}{l}\text { globin/g } \\
\text { after }\end{array}$ & $\begin{array}{l}\text { gdl-3 } \\
\text { change }\end{array}$ & $\begin{array}{l}\text { number of } \\
\text { symptoms }\end{array}$ & $\begin{array}{l}\text { use of acet- } \\
\text { azolamide }\end{array}$ & retinal \\
\hline R.C. & 14.1 & 15.1 & 1.0 & 4. & $Y$ & $\mathrm{~N}$ \\
\hline J.C. & 15.4 & 15.7 & 0.3 & 3 & $\mathrm{~N}$ & $N \frac{T}{2}$ \\
\hline J.H. ${ }^{*}$ & 16.1 & 14.6 & -1.5 & 5 & $\mathrm{~N}$ & $\mathrm{~N}$ 畐 \\
\hline K.H. & 12.8 & 13.7 & 0.9 & 8 & $\mathrm{~N}$ & $\mathrm{~N}^{\mathbb{D}}$ \\
\hline O.H. & 15.8 & 16.6 & 0.8 & 0 & $\mathrm{~N}$ & $Y \vec{D}$ \\
\hline J.H. & 16.4 & 17.5 & 1.1 & 1 & $Y$ & $\mathrm{Y}$ \\
\hline J.L. & 15.2 & 15.3 & 0.1 & 0 & $\mathrm{~N}$ & $\mathrm{Y}$ \\
\hline R.M. & 14.3 & 15.0 & 0.7 & 5 & Y & $\mathrm{N} \Omega$ \\
\hline S.R. & 15.1 & 15.1 & 0.0 & 3 & Y & N응 \\
\hline D.S. & 15.8 & 16.2 & 0.4 & 5 & $\mathrm{~N}$ & $N \leq$ \\
\hline S.S. & 15.2 & 15.6 & 0.4 & 1 & $\mathrm{~N}$ & Yō \\
\hline D.S. & 16.3 & 15.7 & -0.6 & 3 & $\mathrm{Y}$ & $\mathrm{N} \stackrel{+}{\rightleftarrows}$ \\
\hline V.T.* & 13.5 & 12.8 & -0.7 & 6 & Y & $\mathrm{N}$ \\
\hline A.T. & 15.0 & 15.0 & 0.0 & 2 & $\mathrm{~N}$ & $\mathrm{~N}$ \\
\hline
\end{tabular}

difference is not significant $(\mathrm{t}=1.29, \mathrm{v}=12, \mathrm{p}=0.11)$. $\mathrm{T} \overrightarrow{\overrightarrow{\mathrm{P}}}$ proportion of climbers using acetazolamide was greater in the group without haemorrhage (50\% vs $25 \%$ ), althou these numbers are really too small for accurate statisticial analysis. Ranking of the number of sympton experienced by each climber at $6000 \mathrm{~m}$ resulted in statistics of $U_{1}=0$ and $U_{2}=40$ for the group wit haemorrhage and with normal fundi respectively; th difference is significant $\left(\mathrm{U}_{1}=0, \mathrm{U}_{2}=40, \mathrm{n}_{1}=4 \mathrm{n}_{2}=1 \mathrm{e}\right.$ $\mathrm{p}=0.002$ ).

\section{Discussion}

The results of this study show, quite contrary to initiog expectations, that the probability of retinal haemorrhage is significantly higher in the group of climbers who seemed to be relatively well acclimatized, by virtue having fewer symptoms of AMS. Although a severe polycythaemia may cause retinal haemorrhage $(12,130$ ) the acclimatized haemoglobin levels seen in this study $\left(\max 17.0 \mathrm{~g} / \mathrm{dl}^{3}\right.$ ) were not of sufficient magnitude to causo this, and the slight increases seen were not significantw higher in those climbers with haemorrhage. Similarly, it 
would be difficult to assume a causative role for acetazolamide in the pathogenesis of retinal haemorrhage, as it was used less by those with haemorrhage than those without.

So, why should relatively well acclimatized climbers in this study be at higher risk of developing retinal haemorrhage? The retinal haemorrhages seen were not associated with retinal vein occlusion or papilloedema these signs were absent on fundoscopy. This may suggest that although retinal haemorrhage is seen with these signs in the terminal stages of high altitude cerebral oedema (14), it is unlikely that the same factors are causing haemorrhage in this study. Similarly, if low arterial oxygen tensions are correlated to symptoms of AMS, as has been described by some authors (although this is still under debate) (15), then this too could be excluded as a cause from the results of this study.

One major difference, however, in the climbers with haemorrhages was that since they were relatively free from the effects of AMS, they were able to climb much more quickly and exercise with heavier loads, usually being found at the front of the group. This in itself may predispose them to haemorrhage for reasons relating to pressure changes in the retina: Firstly, although altitude in itself does not cause a drop in intra-ocular pressure (8), intra-ocular pressure does fall during bouts of exercise (16), thus intra-ocular pressures may be relatively lower in the more active acclimatized subjects. Secondly, although all climbers will have elevated retinal venous pressure and flow at altitude $(17,18)$, the more active members will have further peaks of venous pressure superimposed on this elevation. This is due to Valsalva effects of high intrathoracic pressures on straining being transmitted directly to the retinal veins, as no venous valves exist between thorax and retina (19). Certainly, severe Valsalva manoeuvres alone can cause retinal haemorrhage in the absence of altitude $(20,21)$, and the clinical picture is not unlike the altitude induced variety (19). One further point in support of exercise-related pressure changes having an aetiology in high altitude retinal haemorrhage, is that it is not observed in subjects whose movements are restricted at altitude or who remain sedentary in simulated altitude chambers, despite showing the other altitude-related vascular changes $(18,22)$

In conclusion, although the results of this study are limited, they do support a theory that high altitude retinal haemorrhage without papilloedema should not be thought of as part of the spectrum of benign mountain sickness, but rather a clinical sign with its own separate aetiology. It should be monitored purely for the sake of preventing long-term damage to the eye, and anyone with a detectable scotoma or progressive haemorrhage should naturally descend with the minimal exertion possible. There is no evidence in this study that it was related to a failure to acclimatize, and so monitoring its appearance as a prognostic indicator of severity of acute mountain sickness appears unsound.

\section{Acknowledgements}

I am very grateful to Col Swanston and HQ-UKLF Southern District Medical Branch for the medicines $\bigcirc$ supplied. Prof Bron lent us an expensive fundus camera 응 from the Oxford Eye Hospital, which we were unfortunately unable to take to altitude due to restrictions $\overrightarrow{\overrightarrow{\mathrm{F}}}$ on weight and power, and Dr Littlewood kindly performed blood analyses at the John Radcliffe Hospital. Finally, the whole exercise would not have been possible $\frac{\bar{\sigma}}{\mathrm{s}}$ without the faultless organisation and planning by $\mathrm{Lt} \mathrm{Col} \approx$ Walker and Capt Barton-Smith at the Oxford University Officers' Training Corps.

\section{REFERENCES}

1. RAVENHILL TH. Some experience of mountain sickness in the Andes. J Trop Med Hyg 1913; 16: 31320.

2. Dickinson JG. Acute mountain sickness. A dissertation based on eleven years' experience in the Nepal Himalaya. D.M. Thesis. University of Oxford, 1981.

3. DiCKINSON JG. Terminology and classification of $\mathcal{G}$ acute mountain sickness. Br Med $J$ 1982; 285: 720-1. 을

4. Singh I, Khanna PK, SRivastava MC, et al. Acutemountain sickness. N Engl J Med 1969; 280: 175-8 $\bar{\Phi}$.

5. Frayser R, Houston CS, Bryan AC, et al. Retina haemorrhage at high altitude. $N$ Engl J Med 197 282: 1183-4.

6. RENNIE DR, MORRISSEY JM. Retinal changes î Himalayan climbers. Arch Ophthalmol 1975; 9. of 395-400.

7. SHULtS WT, Swan KC. High altitude retinopath in mountain climbers. Arch Ophthalmol 1975; 93: 404-8.

8. Clarke C, Duff J. Mountain sickness, retinal $\stackrel{\mathbb{D}}{\stackrel{2}{2}}$ haemorrhages, and acclimatisation on Mount Everest $\vec{\circ}$ in 1975. Br Med J 1976; 2: 495-7.

9. Butler FK, Harris DJ, Reynolds RD. Altitude retinopathy on Mount Everest, 1989. Ophthalmology 1992; 99: 739-46.

10. Hackett PH, Rennie D, Levine HD. The incidence, importance and prophylaxis of acute mountain sickness. Lancet 1976; ii: 1149-51.

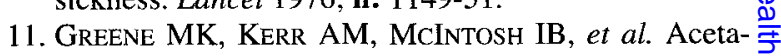
zolamide in prevention of acute mountain sickness: a double-blind controlled cross-over study. $\mathrm{Br} \mathrm{Med} J \stackrel{\mathrm{s}}{3}$ 1981; 283: 811-3.

12. CARR RE, HENkIND P. Retinal findings associated with serum hyperviscosity. Am J Ophthalmol 1963; 옥 56: $23-31$.

13. DUKE-ELDER S, MACFAUL PA. Diseases of the retina. In: A System of Ophthalmology. St. Louis: CV N Mosby \& Co, 1972:

14. Lubin JR, RENNIE D, HaCKetT $P$, et al. High altitude retinal haemorrhage: a clinical and pathological case report. Ann Ophthalmol 1982; 14: 1071-6. 
15. Ward M, Milledge JS, West JB. High altitude medicine and physiology. London: Chapman and Hall, 1989.

16. Lempert P, CoOper KH, Culbert JP, et al. The effect of exercise on intra-ocular pressure. Am J Ophthalmol 1967; 63: 1673-6.

17. HiCKAM JB, FRAYSER R. A study of the retinal venous blood oxygen saturation in human subjects by photographic means. Circulation 1963; 27: 375-85.

18. Frayser R, Houston CS, GRAY GW, et al. The response of the retinal circulation to altitude. Arch Intern Med 1971; 127: 708-11.
19. DUANE TD. Valsalva haemorrhagic retinopathy. J Ophthalmol 1972; 75: 637-42.

20. MARR WG, MARR EG. Some observations Purtscher's disease: traumatic retinal angiopathy. J Ophthalmol 1962; 54: 693-705.

21. SCHIPPER I. Valsalvamanöver: nicht immer gut tig. Klin Mbl Augenheilk 1991; 198: 457-59.

22. Kobrick JL, Appleton B. Effects of extend hypoxia on visual performance and retinal vascu鬼 state. J App Physiol 1971; 31(3): 357-62. 